\title{
Economic Performance Optimization of a PV- BESS Power Generator: A Case Study La Reunion Island
}

\author{
Cédric Damour, Michel Benne*, Frédéric Alicalapa, Brigitte Grondin-Perez, Jean-Pierre Chabriat \\ University of La Reunion, Saint Denis, France \\ Email: ${ }^{*}$ michel.benne@univ-reunion.fr
}

How to cite this paper: Damour, C., Benne, M., Alicalapa, F., Grondin-Perez, B. and Chabriat, J.-P. (2017) Economic Performance Optimization of a PV-BESS Power Generator: A Case Study La Reunion Island. Smart Grid and Renewable Energy, 8, 114128.

https://doi.org/10.4236/sgre.2017.84008

Received: December 8, 2016

Accepted: April 27, 2017

Published: April 30, 2017

Copyright $\odot 2017$ by authors and Scientific Research Publishing Inc. This work is licensed under the Creative Commons Attribution International License (CC BY 4.0).

http://creativecommons.org/licenses/by/4.0/

(c) (i) Open Access

\begin{abstract}
This paper proposes an economic performance optimization strategy for a PV plant coupled with a battery energy storage system. The case study of La Reunion Island, a non-interconnected zone (NIZ) with a high level of renewable energy sources (RES), is considered. This last decade, to reach the ambitious target of electricity autonomy by 2030 set by the local authorities, local and national plans have been launched to promote renewable energy sources integration that led to a noticeable development of photovoltaic (PV) systems. To avoid a decrease of the grid reliability due to a large integration of intermittent energy sources into a non-interconnected grid, the authorities have introduced new regulatory rules for RES producers. The proposed optimization strategy relies on these new regulatory rules and takes into account the energy market data, the amount of PV production subject to penalties for imbalance, the batteries and the PV technological characteristics together with a PV production forecast model. Due to its high convergence rate to the true global minimum and its perfect suitability to practical engineering optimization problems, the recently developed Modified Cuckoo Search algorithm is used as optimization algorithm. The effectiveness and relevance of the proposed strategy are assessed on experimental data collected on a real PV power plant. An economical analysis demonstrates that the proposed optimization strategy is able to fulfill the new regulatory rules requirements while increasing the economic performance of the system.
\end{abstract}

\section{Keywords}

Power System Economic Analysis and Optimization, PV Plant, Battery Energy Storage System, Metaheuristic Optimization Algorithm 


\section{Introduction}

To date, reducing carbon emission has become a major concern. Among possible options, increasing shares of renewable energy sources (RES) such as solar, wind or biomass resources appear as a promising solution for a cleaner power generation. High shares of RES may then become a critical aspect of future energy systems. In this context, small islands that mainly rely on imported fossil fuels for energy production are likely to be pioneers in the development of decarbonized electricity production [1] [2].

In this study, the case of La Reunion Island, a non-interconnected zone (NIZ), is considered. Even if the territory has a high level of RES, its electricity production remains strongly based on imported fuels. In this context, local authorities have set the ambitious objective of reaching electricity autonomy by 2030. This last decade, to reach this target, local and national plans have been launched to promote RES integration [3] [4]. Thus, supported by incentive mechanisms such as tax exemptions, direct subsidies or feed-in tariffs, photovoltaic (PV) systems have experienced a rapid and noticeable development [5]. However, a large integration of intermittent sources into a non-interconnected grid raises critical technical issues due to the uncertainties of the energy production. The intermittency and unreliability of solar-generated power may reduce the network stability and lead to load shedding or to the interruption of electric service [6]. To avoid such situations, the authorities have set a limit of $30 \%$ of intermittent sources in the instantaneous electricity production and have introduced new regulatory rules for RES development. Henceforth, RES producers have to declare to the grid operator, a day in advance, the power profile that will be injected to the grid. Then, if the power plants do not meet the submitted schedule for injected power, they face financial penalties. In La Reunion Island, if mismatches between actual and scheduled power injection exceed a given tolerance, RES producers are charged with imbalance penalties. In order to address the problem related to the intermittency of solar-generated electricity while reducing the amount of PV production subject to penalties for imbalance, energy storage systems (ESSs) appears as one of the most relevant option. Recently, several works related to the applicability, advantages and disadvantages of various ESS technologies for RES integration have been reported [7]. As regards PV power plants coupling with ESS, several works dealing with technical issues and economic feasibility have been conducted [8] [9] [10] [11]. However, from a regulatory point of view (incentive schemes and economic feasibility), nearly all works reported in the literature focus on the determination of the optimal sizing of the ESS [12] [13] [14] [15].

In the case of La Reunion, and according to our best knowledge, none work has been conducted to optimize the economical performance of existing hybrid photovoltaic-battery energy storage system (BESS) power generators, based on the latest regulatory rules. In this paper, an economical optimization of a hybrid PV-BESS power generator is developed. The proposed methodology relies on a metaheuristic optimization algorithm taking into account the energy market da- 
ta, the amount of PV-generated energy subject to penalties for imbalance, the $\mathrm{PV}$ and the batteries technological characteristics together with a PV production forecast model. To assess the effectiveness and relevance of the proposed strategy, the economic analyses are performed on data measured on a real power plant. Indeed, a one-year experimental data, collected from August 2013 to August 2014 on a $57 \mathrm{kWp}$ PV farm coupled with a $78.5 \mathrm{kWh}$ BESS, are considered.

The rest of this paper is organized as follows. The regulatory rules applied in La Reunion are presented in Section 2. Section 3 is dedicated to model design. In this section the PV production forecast model and the energy storage model are detailed. The performance of the proposed optimization strategy in terms of economical efficiency improvement is demonstrated in Section 4.

\section{Regulatory Rules}

In non-interconnected zones (NIZ) such as La Reunion, the large integration of intermittent sources raises critical technical issues issue related to the reliability of power supply. The reliability of an electrical grid can be defined by its ability to supply the aggregate electrical demand and energy requirements of the customers at all times, while withstanding sudden disturbances such as unanticipated loss of system elements (e.g. load or production fluctuations) [16] [17] [18]. Currently the reliability of power supply in La Reunion is already lower than in Metropolitan France. In La Reunion the average duration of electricity not supplied is estimated at $4 \mathrm{~h}$ /year/consumer compared to $73 \mathrm{~min}$ in Metropolitan France [5].

In this context, and considering the rapid and important growth of PV systems in La Reunion the last decade, the authorities have recently decided to set up new regulatory rules to ensure the reliability of the power supply. Henceforth, producers have to declare a time generation profile that represents the day-ahead power injected by their plants, at a minute basis. If the mismatches between the actual injected power and the announced power exceed the admitted tolerance, financial penalties are applied. According to this regulatory framework, energy imbalance is calculated with minutely resolution, and the tolerance band is taken equal to $\pm 5 \%$ of the installed PV power capacity $\left(P_{\mathrm{PV}_{\text {_peak }}}\right)$.

The electricity tariff system relies on peak and off-peak hours. During peak hours, 7 PM to 9 PM, the electricity feed-in tariff is more attractive. However, during this time period, producers have to guarantee a constant power injection to the grid comprised between $20 \%$ and $70 \%$ of $P_{\mathrm{PV}_{-} \text {peak }}$. The current electricity tariff system applied to PV power producers in La Reunion, including peak and off-peak feed-in tariffs, is summarized in Table 1.

Table 1. Summary of tariff system in La Reunion.

\begin{tabular}{ccc}
\hline & $\begin{array}{c}\text { Peak hours (7 PM to 9 PM) } \\
{[€ \mathrm{ct} / \mathrm{kWh}]}\end{array}$ & $\begin{array}{c}\text { Off-peak hours } \\
{[€ \mathrm{ct} / \mathrm{kWh}]}\end{array}$ \\
\hline Selling price $\left(C_{s}\right)$ & 60 & 40 \\
Buying price $\left(C_{b}\right)$ & 40 & 40 \\
\hline
\end{tabular}


Note that producers have the possibility to buy electricity from the grid. In some very specific cases, it could be interesting to buy electricity from the grid during off-peak, store the energy in an ESS, and sell it back during peak hours.

The producer's revenue is calculated each minute using the follow expression:

$$
\text { revenue }=P_{\text {inj }} C_{S} / 60-P_{\text {out }} C_{b} / 60-\text { penalties }
$$

where $P_{i n j}$ denotes the power injected to the grid, $P_{\text {out }}$ the power extracted from the grid, and the financial penalties are calculated as follows:

$$
\text { if } \begin{gathered}
P_{b i d}-0.05 P_{\mathrm{PV} \_ \text {peak }}<P_{\text {inj }}<P_{\text {bid }}+0.05 P_{\mathrm{PV}_{-} \text {peak }} \text { then } \\
\text { penalties }=0
\end{gathered}
$$

else if $P_{i n j}>P_{\text {bid }}+0.05 P_{\mathrm{PV} \_ \text {peak }}$ then

$$
\text { penalties }=P_{i n j} C_{S} / 60
$$

else

penalties $=\frac{C_{s}}{60}\left[P_{i n j} \frac{P_{i n j}}{P_{\mathrm{PV}_{\text {peak }}}}-\left(0.1+\frac{2 P_{b i d}}{P_{\mathrm{PV}_{\text {peak }}}}\right) P_{i n j}+\left(P_{b i d}-0.05 \times P_{\mathrm{PV}_{-} \text {peak }}\right)\left(0.015-\frac{P_{b i d}}{P_{\mathrm{PV}_{\text {peak }}}}\right)\right]$ end if

where $P_{b i d}$ denotes the day-ahead schedule power profile to be injected to the grid.

Every time $P_{i n j}$ is outside the tolerance band, the system is said to be in faulty condition and financial penalties are applied.

In this work, the economic effectiveness of the system is assessed using two criteria, which are the revenue and the daily fault rate $(D F R)$. This last criterion defines the ratio of time where the system is in faulty condition each day:

$$
\mathrm{DFR}=\tau_{\text {fault }} / 1440
$$

With $\tau_{\text {fault }}$ the cumulated time of fault condition in minute.

To fulfill the requirements of the new regulatory rule, PV power producers have to announce a day in advance the power profile to be injected to the grid, which requires a PV production forecast model. Besides, regardless of the accuracy of the PV production forecast model, financial penalties due to imbalance are unavoidable. Therefore, to reduce financial penalties and above all take advantage of peak hours feed-in tariff, the use of ESS appears to be a relevant option.

\section{Model Design}

\subsection{PV Production Forecast Model}

In the literature, a wide variety of parametric and non-parametric forecast models have been reported [19]. Parametric models require a wide set of information about the PV power plant technology and its installation configuration. Nonparametric models are generally based on weather forecast models [20]. These limitations make the reliability and the suitability for "on field" uses of parametric and non-parametric forecast models questionable (Table 2).

In this study, regarding practical purposes, the widely used persistence model is chosen to forecast the PV output power at a minute basis. This is a simple 
Table 2. Nomenclature.

\begin{tabular}{|c|c|}
\hline Variable & Description [Unity] \\
\hline$P_{\text {bid }}$ & Scheduled profile to be injected to the grid $[\mathrm{kW}]$ \\
\hline$P_{i n j}$ & Power injected to the grid $[\mathrm{kW}]$ \\
\hline$P_{\mathrm{PV}_{-} m}$ & Measured PV power $[k W]$ \\
\hline$P_{\mathrm{PV}_{-} f}$ & Forecasted $P V$ power $[\mathrm{kW}]$ \\
\hline$P_{\text {PV_peak }}$ & Installed $P V$ power capacity $\left[k W_{p}\right]$ \\
\hline$P_{s t o}$ & Storage power $[k W](>0$ charge, $<0$ discharge $)$ \\
\hline$P_{\text {sto } A C}$ & Storage power exchanged with the AC bus \\
\hline$-P_{d}$ & Maximal power in discharge $[\mathrm{kW}]$ \\
\hline$P_{c}$ & Maximal power in charge $[\mathrm{kW}]$ \\
\hline$P_{I}$ & Imbalance power $[\mathrm{kW}]$ \\
\hline$E_{\text {sto_ peak }}$ & Amount of energy dedicated to evening peak $[\mathrm{kWh}]$ \\
\hline$E_{\mathrm{PV}_{-} f_{-} \text {total }}$ & Estimated total energy produced by $P V$ plant $[k W h]$ \\
\hline$\alpha_{\text {peak }}$ & Parameter to be estimated \\
\hline$\beta_{\text {forecast }}$ & Parameter to be estimated \\
\hline$C_{\max }$ & Maximum usable storage capacity $[k W h]$ \\
\hline$S O C_{\min }$ & Min. energy storage level $\left[\begin{array}{ll}\% & C_{\max }\end{array}\right]$ \\
\hline$S O C_{\max }$ & Max. energy storage level $\left[\% C_{\max }\right]$ \\
\hline$\eta_{c}$ & Efficiency of storage in charge \\
\hline$\eta_{d}$ & Efficiency of storage in discharge \\
\hline$C_{s}$ & Electricity selling price \\
\hline$C_{b}$ & Electricity buying price \\
\hline$D F R$ & Daily fault rate \\
\hline$\tau_{\text {fault }}$ & Cumulated time of faulty condition [minute] \\
\hline
\end{tabular}

model based on the assumption that the PV production of today is the same as yesterday [21]:

$$
P_{\mathrm{PV}_{-} f}(t)=P_{\mathrm{PV}_{-} m}(t-1440)
$$

where $P_{\mathrm{PV}_{-} f}(t)$ and $P_{\mathrm{PV}_{-} m}(t)$ denotes respectively the measured and forecast PV output power at time $t$.

Even if this method does not take into account the intra-day variability of solar irradiance, it represents with a good accuracy the periodicity and seasonality of weather conditions (day/night and summer/winter cycles) [13]. Besides, it has the merit of introducing no incremental cost, which cannot be underestimated for small cases applications. Obviously, the accuracy of the PV production forecast could be improved using more sophisticated models but at the price of increasing complexity and computational cost.

\subsection{Energy Storage Model}

Regarding optimization purposes and according to the considered time scale 
Table 3. Storage system parameters values.

\begin{tabular}{ccc}
\hline Variable & Description [Unity] & Value \\
\hline$C_{\max }$ & Maximum storage capacity $[\mathrm{kWh}]$ & 78.5 \\
$S O C_{\min }$ & Min. energy storage level $\left[\% C_{\max }\right]$ & 20 \\
$S O C_{\max }$ & Max. energy storage level $\left[\% C_{\max }\right]$ & 99 \\
$\eta_{c}$ & Efficiency of storage in charge & 0.9 \\
$\eta_{d}$ & Efficiency of storage in discharge & 0.9 \\
$-P_{d}$ & Maximal power in discharge $[\mathrm{kW}]$ & 36.1 \\
$P_{c}$ & Maximal power in charge $[\mathrm{kW}]$ & 17.2 \\
$D O D_{\max }$ & Maximal depth of discharge $[\%]$ & 80 \\
\hline
\end{tabular}

(minutes in this study), a simplified static model is proposed. This model relies on the static characteristics of the battery ( $C f$. Table 3 ) and neglects the transient dynamics of the process. In the sequel, powers are considered negative (respectively positive) during the discharge (respectively charge) phase. In this context, the battery state of charge (SOC) at time $t$ is computed by:

$$
\operatorname{SOC}(t)=\operatorname{SOC}(t-\Delta t)+P_{\text {sto }}(t) \times \Delta t / C_{\max }
$$

Subjected to constraints on power and capacity:

$$
\left\{\begin{array}{l}
P_{d} \leq P_{\text {sto }}(t) \leq P_{c} \\
S O C_{\text {min }} \leq S O C(t) \leq S O C_{\text {max }}
\end{array}\right.
$$

where $P_{\text {sto }}(t)$ is the storage power at time $t . P_{d}<0,-P_{d}$ represents the maximum battery discharging power, and $P_{c}>0$ the maximum battery charging power. $S O C_{\min }$ and $S O C_{\max }$ are the minimum and maximum battery state of charge, respectively. $C_{\max }$ denotes the maximum usable storage capacity of the ESS. Note that the battery aging and self-discharge rate, which obviously affect $C_{\max }$, has not been considered. Besides, powers are considered constant during the time interval $[t, t+\Delta t]$. In this work, $\Delta t$ is equal to one minute.

The PV, battery, grid, and loads are all connected to an AC bus. Since the battery is operated on DC, an AC-to-DC (respectively DC-to-AC) converter is necessary when charging (respectively discharging) the battery. Therefore, considering the storage charge and discharge efficiencies $\left(\eta_{c}\right.$ and $\eta_{d}$ respectively), the storage power exchanged with the AC bus $P_{\text {sto_AC }}(t)$ is expressed as follows:

$$
\begin{array}{ll}
P_{\text {sto } A \text { AC }}(t)=P_{\text {sto }}(t) \eta_{d} & \text { if } P_{\text {sto }}(t)<0 \text { (discharge) } \\
P_{\text {sto }}(t)=P_{\text {sto }}(t) / \eta_{c} & \text { if } P_{\text {sto }}(t) \geq 0 \text { (charge) }
\end{array}
$$

\section{Economic Performance Optimization}

In this work, a minute dispatch strategy for a $57 \mathrm{kWp} \mathrm{PV}$ farm with $78.5 \mathrm{kWh}$ BEES is implemented and an economical optimization of the dispatch strategy is proposed. BESS has two main applications: first, compensate PV production 
forecast errors during off-peak and thus reduce financial penalty due to imbalance. Second, inject power to the grid during peak hours and thus take advantage of the attractive feed-in tariff.

In this context, two parameters are introduced. The first one, denoted $\alpha_{\text {peak }}$, is related to the amount of energy dedicated to the evening peak hours $\left(E_{\text {sto_peak }}\right)$, which have to be stored in the BESS meanwhile, and is written as a fraction of the estimated total energy produced by the PV plant $\left(E_{\mathrm{PV}_{-} f_{-} \text {total }}\right)$ :

$$
E_{\text {sto_peak }}=\alpha_{\text {peak }} E_{\mathrm{PV}_{-} f_{-} \text {total }}
$$

Here $\quad E_{\mathrm{PV}_{-} f_{-} \text {total }}=\int_{0}^{1440} P_{\mathrm{PV}_{-} f} \mathrm{~d} t$. The second one, denoted $\beta_{\text {forecast }}$, represents the fraction of the storage capacity that is dedicated to compensate power imbalance $\left(C_{\text {foreacast }}\right)$ due to forecast errors:

$$
C_{\text {foreacast }}=\beta_{\text {forecast }} C_{\max }
$$

To assess the effectiveness and relevance of the proposed strategy, the economic analyses are performed on a one-year experimental data, collected from August 2013 to August 2014 at La Reunion on a real PV power plant. Due to its high convergence rate to the true global minimum and its perfect suitability to practical engineering optimization problems, the recently developed Modified Cuckoo Search algorithm proposed by [22] is used as optimization algorithm.

\subsection{Modified Cuckoo Search Algorithm}

Modified Cuckoo Search (MCS) algorithm can be regarded as a modification of the standard Cuckoo Search (CS) proposed by Yang and Deb [23] to increase its convergence rate and makes it more suitable for practical engineering optimization problems.

CS algorithm relies on the observation of the reproduction strategy of cuckoos. Cuckoos lay their eggs in the nests of other host birds that may be of different species. If the host bird discovers that the eggs are not its own it could either destroy the egg or abandon the nest [24]. To apply this as an optimization tool, Yang and Deb [23] used three idealized rules:

- Each cuckoo lays one egg (a set of solution) at a time and dumps it in a random nest;

- The best nests, those containing the highest quality of eggs (solutions), will carry over to the next generation;

- The number of nests is fixed, and there is a probability $p \in[0,1]$ that a host discovers an alien egg. If this happens, the host can either discard the egg or the nest, and builds a new nest in a new location (new random solutions at new locations).

The main modification introduced by [22] consists in adding information exchange between the top eggs or the best solutions to increase the convergence rate of the method and extend its applicability to a wider range of applications. Standard optimization benchmarking functions have been used to test the effects of this modification and it has been demonstrated that, in most cases, the MCS performed as well as, or better than, the standard CS, a particle swarm optimizer, 
and a differential evolution strategy. MCS and CS algorithms and their performance compared to other standard optimization strategies are fully detailed in [22].

\subsection{PV/BESS Control Rules}

The power injected to the grid is defined as the sum of the PV output power and the storage power exchanged with the AC bus:

$$
P_{\text {inj }}=P_{\mathrm{PV}_{-} m}+P_{\text {sto_AC }}
$$

The BESS is used to adjust the PV power plant $P_{\mathrm{PV}_{-} m}$ to maintain, as much as possible, the difference between the day-ahead announcement $P_{b i d}$ and the actual power injected $P_{i n j}$ to the grid within the tolerance band. If $P_{\mathrm{PV}_{-} m}$ is above (respectively below) the tolerance limit, the BESS can be used, when it is possible, to store (respectively deliver) the imbalance power $P_{I}$. Depending on whether the measured output PV is within, below or above the tolerance band, $P_{I}$ is defined as follows:

$$
\begin{cases}P_{I}=0 & \text { within } \\ P_{I}=P_{\mathrm{PV}_{-m}}-\left(P_{b i d}+0.05 P_{\mathrm{PV}_{\text {Peak }}}\right) & \text { above(charge) } \\ P_{I}=P_{\mathrm{PV}_{-} m}-\left(P_{b i d}-0.05 P_{\mathrm{PV}_{\text {Peak }}}\right) & \text { below (discharge) }\end{cases}
$$

Every time $P_{I} \neq 0$ financial penalties for imbalance are applied. Therefore, the storage charge/discharge process must be suitably controlled in order to reduce the DFR and thereby the amount of financial penalties, while ensuring that there is enough energy stored in the BESS for the evening peak. In this aim, a tolerance band control strategy is proposed and a specific control rules is designed for each zone: above, within and below the band.

\section{Above the upper limit}

When $P_{\mathrm{PV}_{-} m}$ is above the tolerance band, the BESS is used to compensate the imbalance power and store the excess of energy whenever possible. Indeed, the imbalance power cannot always be compensated. Several conditions related to operational and technical limits of the BESS have to be verified (i.e state of charge, charge/discharge rate limits). In this case, the storage power is computed as follows:

$$
P_{\text {sto_AC }}=\min \left(P_{c} / \eta_{c}, P_{I}, P_{\text {sto_MAX }} / \eta_{c}\right)
$$

where $P_{\text {sto_MAX }}=\left(S O C_{\max }-S O C(t)\right) C_{\max } / \Delta t$

\section{Below the lower limit}

When $P_{\mathrm{PV}_{-} m}$ is below the tolerance band, the imbalance power due to forecast error can be compensated using the energy stored in the BESS. However, this energy has to be manipulated very wisely in order to ensure that enough energy remains to guarantee peak hours. The storage power is calculated according to operational and technical limits of the BESS and subjected to con-

$$
\begin{aligned}
& \text { straints on } E_{\text {sto_peak }} \text { and } C_{\text {foreacast }} \text { : } \\
& \text { if } \operatorname{SOC}(t)>E_{\text {sto peak }} / C_{\max } \text { then } \\
& \qquad P_{\text {sto_AC }}=\max \left(P_{d} \eta_{d}, P_{I},-P_{\text {sto_MAX }} \eta_{d}\right)
\end{aligned}
$$


else

$$
P_{\text {sto_AC }}=0
$$

end if

where $P_{\text {sto_MAX }}=\min \left(\left(\operatorname{SOC}(t)-E_{\text {sto_peak }} / C_{\max }\right) C_{\max } / \Delta t, C_{\text {foreacast }} / \Delta t\right)$

Within the tolerance band

When $P_{\mathrm{PV}_{-} m}$ is within the tolerance band, the power imbalance is equal to zero and there is not need to absorb/inject power from/to the grid through the BESS:

$$
P_{\text {sto_AC }}=0
$$

\subsection{Economic Performance Improvement}

The economical performance improvement relies on the estimation of two parameters $\alpha_{\text {peak }}$ and $\beta_{\text {forecast }}$. The effects of these parameters on the annual revenue and the average annual $D F R$ are illustrated on Figure 1 and Figure 2.

As expected, while $\beta_{\text {forecast }}$ is increasing the DFR is decreasing. Indeed, $\beta_{\text {forecast }}$ is straightforwardly linked to the fraction of the storage capacity dedicated to compensate power imbalance due to forecast errors. However, it is important to highlight that decreasing the DFR and so the financial penalties do not necessary means increasing the revenue. In fact, while $\beta_{\text {forecast }}$ is increasing, the amount of energy that can be stored in the BESS for the evening peak hours decreases since $C_{\text {foreacast }}$ becomes closer to $C_{\max }$ (Cf. Equation (8)). Indeed, Figure 1 illustrates that it could be more interesting to sell more energy during peak hours even if that means paying more penalties during off-peak due to forecast error. Which can be explained by the fact that peak hours feed-in tariff is more attractive than off-peak one.

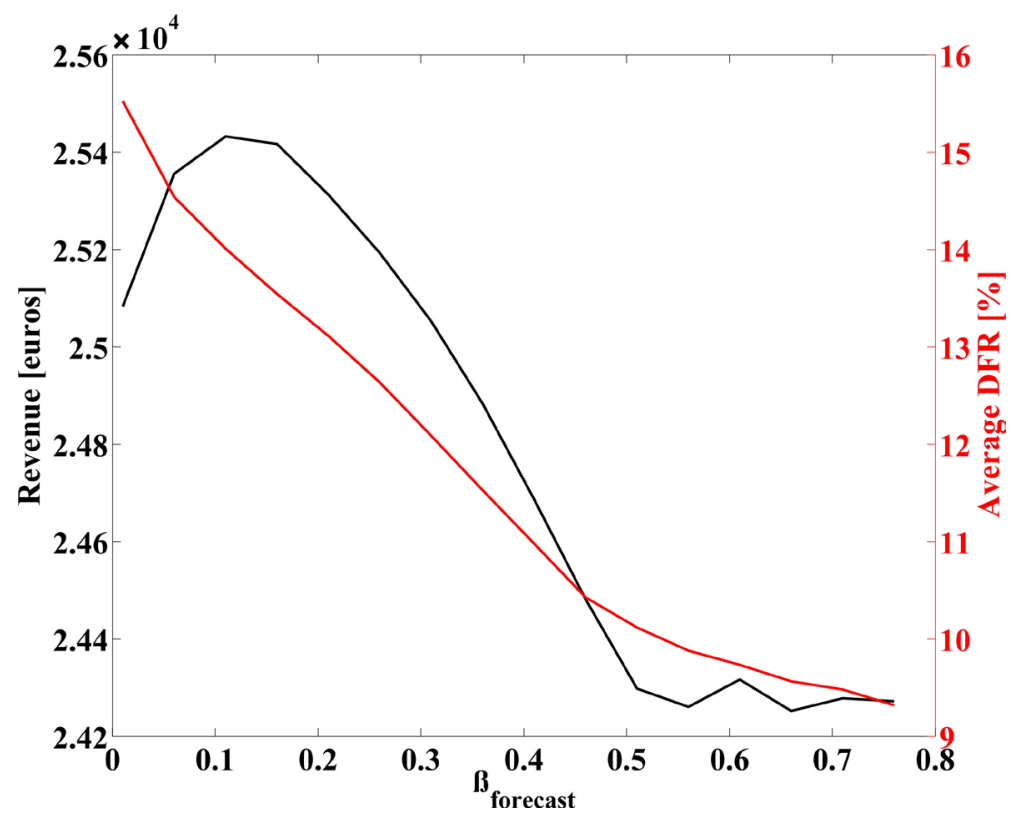

Figure 1. Effects of $\beta_{\text {forecast }}$ on the revenue and the DFR (with $\alpha_{\text {peak }}=0.3$ and calculated over one year). 


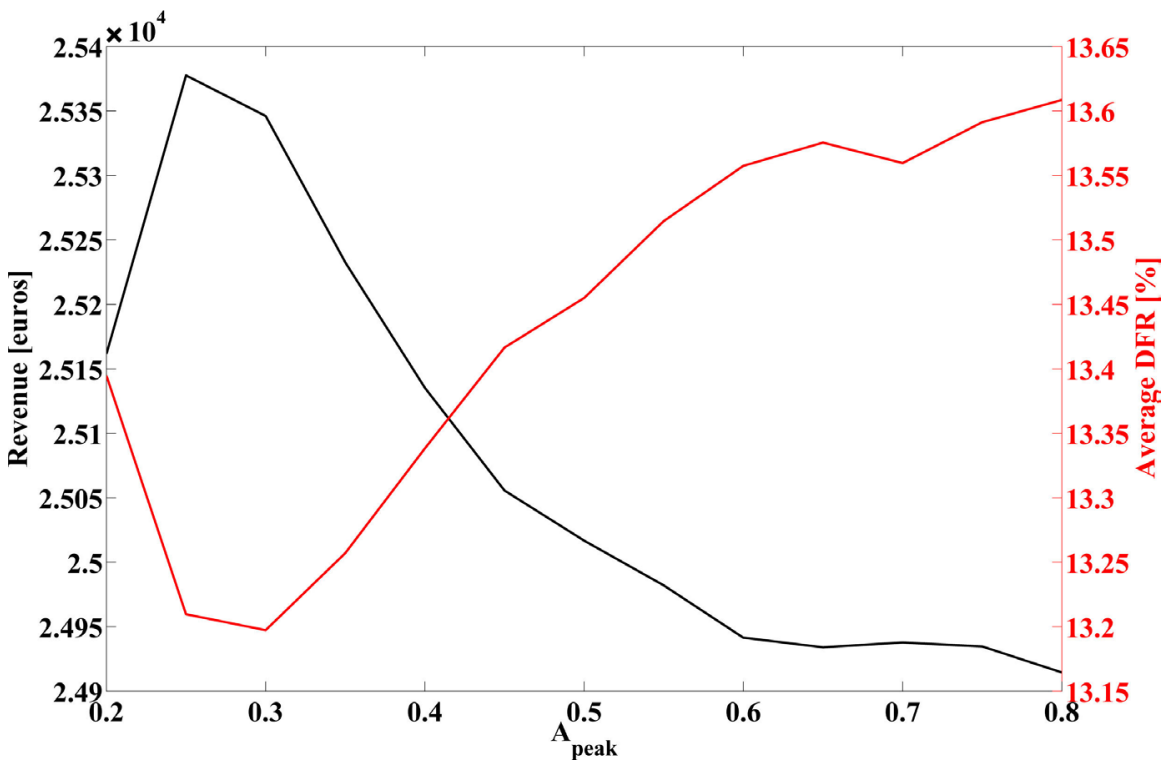

Figure 2. Effects of $\alpha_{\text {peak }}$ on the revenue and the DFR (with $\beta_{\text {forecast }}=0.2$ and calculated over one year).

As illustrated on Figure 2, while $\alpha_{\text {peak }}$ is increasing the DFR is increasing, whereas the revenue increasing to a maximum before decreasing. Which seems indicate that, for a fixed value of $\beta_{\text {foreast }}$, there is an optimal amount of energy to store in the BESS for the evening peak hours.

\subsection{Annual Optimization}

In a first attempt, the economic performance improvement strategy consists on finding the optimal values of $\alpha_{\text {peak }}$ and $\beta_{\text {forecast }}$ that maximizes the annual revenue. The optimization goal is to find the optimal set of parameter $\hat{p}=\left[\alpha_{\text {peak }} \beta_{\text {forecast }}\right]^{\mathrm{T}}$ that maximizes the cost function $J$ :

$$
\hat{p}=\arg \max _{p}(J)
$$

with $J=\sum_{j=1}^{365} \sum_{i=1}^{1440}\left(P_{i n}^{i, j} \times C_{s} / 60-P_{\text {out }}^{i, j} \times C_{b} / 60-\right.$ Penalties $\left.^{i, j}\right)$

and subjected to

$$
p \in\left[p_{\min }, p_{\max }\right] ; p_{\min }=[00]^{\mathrm{T}} ; p_{\max }=[10.8]^{\mathrm{T}}
$$

The optimization procedure, performed on experimental data collected from August $31^{\text {st }} 2013$ to September $1^{\text {st }} 2014$, leads to the optimal set of parameter $\hat{p}=[0.29780 .1387]^{\mathrm{T}}$, which results to an annual revenue of 25449.20 euros and an average $D F R$ of $13.12 \%$. The revenue and the $D F R$ for each day are presented in Figure 3.

It can be noticed that the DFR seems to contain a periodic component. The analysis of the DFR in the frequency domain reveals that the frequency component with the higher magnitude is located at 0.002732 day $^{-1}$, which corresponds to a periodicity of 366 days. Moreover, a thorough study of the DFR reveals a strong and significant correlation between DFR and the forecast error, with a Pearson's correlation coefficient of $82 \%$ ( $p$-value $<0.0001)$. 

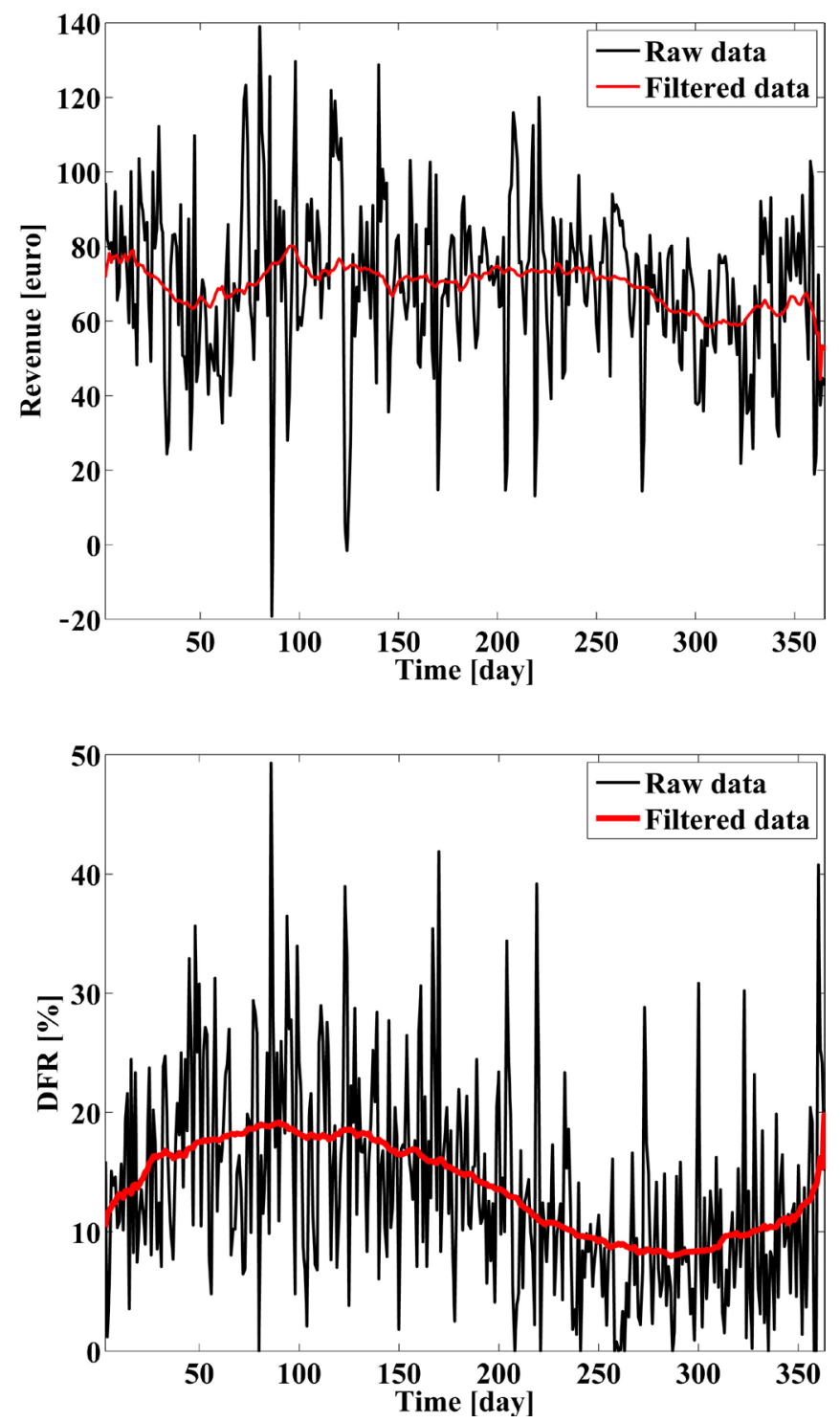

Figure 3. Daily revenue and DFR obtain over one year.

The analysis of the forecast error reveals the same periodicity of 366 days, which means that the forecast error is linked to the season. Indeed, as illustrated on Figure 4, the forecast error is higher in summer than in winter. This can be mainly explained by the fact that the forecast model does not take into account the intra-day variability of solar irradiance and that in La Reunion Island the intra-day variability is higher in summer. In this context, when the intra-day variability increases the error modeling increases too, which leads to an increase of the $D F R$. In other worlds, the seasonality of the solar irradiance variability introduces a seasonal component into the forecast error that is transmitted to the DFR.

The analysis of the total energy produced by the PV plant each day $\left(E_{\mathrm{PV}_{-} f_{-} \text {total }}\right)$ reveals a seasonal component that is due to the yearly solar irradiance variability ( $C f$. Figure 5 ). The amount of energy dedicated to the peak hours $\left(E_{\text {sto_peak }}\right)$, which could have a strong influence on the revenue, is taken as a fraction of $E_{\mathrm{PV}_{-} f_{-} \text {total }}$ using $\alpha_{\text {peak }}$. In this context, the seasonal compo- 


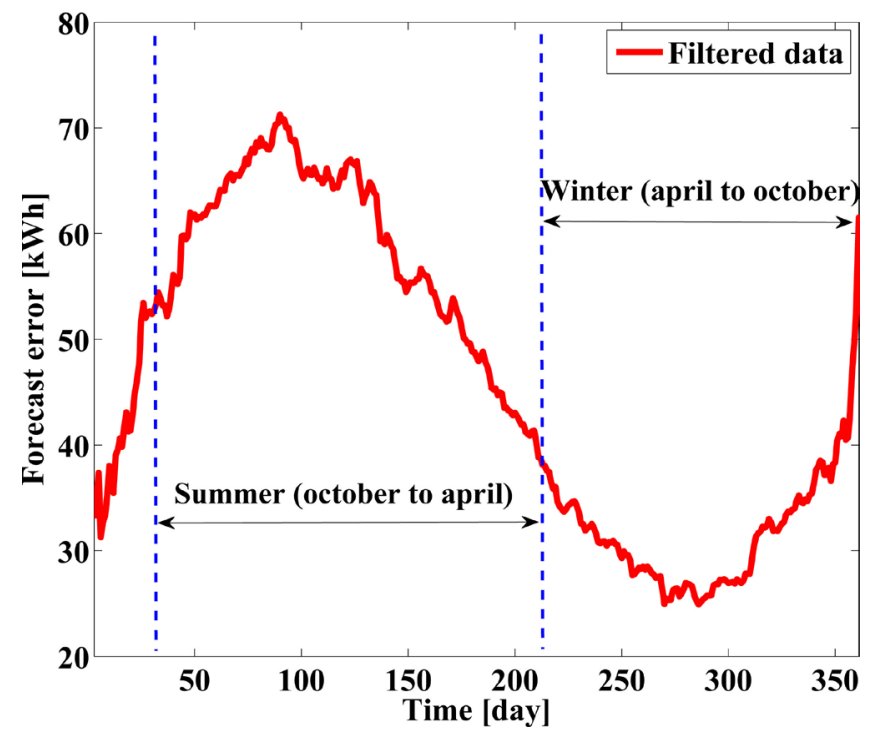

Figure 4. Forecast error.

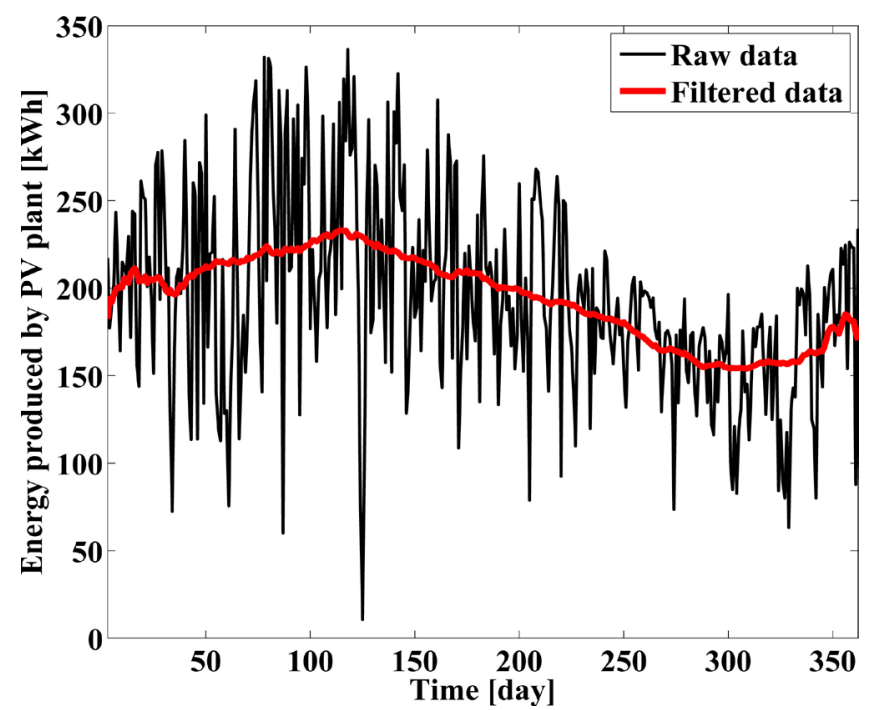

Figure 5. Energy produced by the PV plant.

nent contained into $E_{\mathrm{PV}_{-} f_{-} \text {total }}$ is transmitted to $E_{\text {sto_peak }}$. A thorough study of intra-day and yearly irradiance variability in La Reunion can be consulted in [25].

Regarding the seasonality of the solar irradiance, and since $\beta_{\text {forecast }}$ and $\alpha_{\text {peak }}$ respectively influence the $D F R$ and the amount of energy dedicated to the peak hours, it is likely that a seasonal-based or even a daily-based optimization of these parameters could increase the revenue.

\section{Conclusions and Prospects}

In this work, a minute dispatch strategy for a $57 \mathrm{kWp}$ PV farm with $78.5 \mathrm{kWh}$ BEES has been simulated, and an economical optimization of the dispatch strategy has been developed. This strategy has been designed to fulfill the requirements of the new regulatory rules set in La Reunion while optimizing the eco- 
nomic performance of the system. The BESS is used during off-peak to compensate PV production forecast error and during peak hours to inject power to the grid. Therefore, two parameters have been introduced. The first one is related to amount of energy to store for the evening peak hours whereas the second one represents the fraction of the storage capacity that is dedicated to compensate power imbalance due to forecast errors. The optimization goal is to find the optimal value of these parameters that maximizing the revenue while taking into account the new regulatory rules constraints. The proposed optimization strategy takes into account the energy market data, the amount of PV production subject to penalties for imbalance, the batteries and the PV technological characteristics together with a PV production forecast model. The effectiveness and relevance of the proposed strategy have been assessed on experimental data collected on a real PV power plant. An economical analysis demonstrated that the proposed optimization strategy has been able to fulfill the new regulatory rules requirements while increasing the economic performance of the system.

Due to the seasonal behavior of solar radiation, it is likely that economical performance can be further increased using a seasonal-based optimization approach. Additional works are currently in progress to study if the revenue can be increased by taking into account the seasonal component contained in the forecast error and the total energy produced by the PV plant.

\section{Acknowledgements}

This work is a contribution to the FEDER project GYSOMATE funded by the European Social Fund and the Reunion Region. The authors would like to kindly acknowledge Pr. Jean-Daniel Lan-Sun-Luk for the fruitful scientific discussions and M. Patrick Jeanty for the solar experimental data.

\section{References}

[1] Weisser, D. (2004) On the Economics of Electricity Consumption in Small Island Developing States: A Role for Renewable Energy Technologies? Energy Policy, 32, 127-140.

[2] Guerassimoff, G., Maïzi, N. and Mastère, O.S.E. (2008) Îles et Énergie: Un Paysage de Contrastes. Les Presses-MINES Paris Tech.

[3] Petrel, A. (2009) Île de la Réunion. Plan économique de Transition et de Relance via des énergies 100\% Locales île de la Réunion. Technical Report.

[4] Praene, J.P., David, M., Sinama, F., Morau, D. and Marc, O. (2011) Renewable Energy: Progressing towards a Net Zero Energy Island, the Case of Reunion Island. Renewable \& Sustainable Energy Reviews, 16, 426-442.

[5] Drouineau, M., Assoumou, E., Mazauric, V. and Maïzi, N. (2015) Increasing Shares of Intermittent Sources in Reunion Island: Impacts on the Future Reliability of Power Supply. Renewable and Sustainable Energy Reviews, 46, 120-128.

[6] Fesquet, F., Juston, P. and Garzulino, I. (2003) Impact and Limitation of Wind Power Generation in an Island Power System. IEEE Bologna Power Technical Conference, Bologna, 23-26 June 2003, 7.

[7] Beaudin, M., Zareipour, H., Schellenberglabe, A. and Rosehart, W. (2010) Energy Storage for Mitigating the Variability of Renewable Electricity Sources: An Updated 
Review. Energy for Sustainable Development, 14, 302-314.

[8] Delfanti, M., Falabretti, D., Merlo, M. and Monfredini, G. (2014) Distributed Generation Integration in the Electric Grid: Energy Storage System for Frequency Control. Journal of Applied Mathematics, 2014, Article ID: 198427.

[9] Weiss, T. and Schulz, D. (2013) Development of Fluctuating Renewable Energy Sources and Its Influence on the Future Energy Storage Needs of Selected European Countries. 4th International Youth Conference on Energy, Siofok, 6-8 June 2013.

[10] Alam, M.J.E., Muttaqi, K.M. and Sutanto, D. (2013) Mitigation of Rooftop Solar PV Impacts and Evening Peak Support by Managing Available Capacity of Distributed Energy Storage Systems. IEEE Transactions on Power Systems, 28, 3874-3884. https://doi.org/10.1109/TPWRS.2013.2259269

[11] Hill, C.A., Such, M.C., Chen, D., Gonzalez, J. and Grady, W.M. (2012) Battery Energy Storage for Enabling Integration of Distributed Solar Power Generation. IEEE Transactions on Smart Grid, 3, 850-857. https://doi.org/10.1109/TSG.2012.2190113

[12] Ru, Y., Kleissl, J. and Martinez, S. (2015) Storage Size Determination for GridConnected Photovoltaic Systems. IEEE Transactions on Sustainable Energy, 4, 6881. https://doi.org/10.1109/TSTE.2012.2199339

[13] Delfanti, M., Falabretti, D. and Merlo, M. (2015) Energy Storage for PV Power Plant Dispatching. Renewable Energy, 80, 61-72.

[14] Cervone, A., Santini, E., Teodori, S. and Romito, D.Z. (2015) Impact of Regulatory Rules on Economic Performance of PV Power Plants. Renewable Energy, 74, 78-86.

[15] Bridier, L., David, M. and Lauret, P. (2014) Optimal Design of a Storage System Coupled with Intermittent Renewable. Renewable Energy, 67, 2-9.

[16] European Network of Transmission System Operators for Electricity (2004) Operation Handbook. Technical Report.

[17] Bergen, A.R. and Vittal, V. (2000) Power System Analysis. 2nd Edition, PrenticeHall Series, Englewood Cliffs.

[18] Bornard, P., Pavard, M. and Testud, G. (2005) Réseaux d'interconnexion et de transport: Fonctionnement. Techniques de P ingénieur, D4091, 1-12.

[19] Perez, R., Lorenz, E., Pelland, S., Beauharnois, M., Knowe, G.V., Hemker, K., et al. (2013) Comparison of Numerical Weather Prediction Solar Irradiance Forecasts in the US, Canada and Europe. Journal of Solar Energy Engineering, 94, 305-326.

[20] Almeida, M.P., Perpinan, O. and Narvarte, L. (2015) PV Power Forecast Using a Nonparametric PV Model. Solar Energy, 115, 354-368.

[21] Lorenz, E., Scheidsteger, T., Hurka, J., Heinemann, D. and Kurz, C. (2011) Regional PV Power Prediction for Improved Grid Integration. Progress in Photovoltaics. Research and Applications, 19, 757-771. https://doi.org/10.1002/pip.1033

[22] Walton, S., Hassan, O., Morgan, K. and Brown, M.R. (2011) Modified Cuckoo Search: A New Gradient Free Optimisation Algorithm. Chaos, Solitons \& Fractals 44, 710-718.

[23] Yang, X.S. and Deb, S. (2009) Cuckoo Search via Lévy Flights. Proceedings of World Congress on Nature \& Biologically Inspired Computing, India, 9-11 December 2009, 210-214.

[24] Yang, X.S. and Deb, S. (2010) Engineering Optimisation by Cuckoo Search. International Journal of Mathematical Modelling and Numerical Optimisation, 1, 330 343. https://doi.org/10.1504/IJMMNO.2010.035430 
[25] Jeanty, P., Delsaut, M., Trovalet, L., Ralambondrainy, H., Lan-Sun-Luk, J.D., Bessafi, M., Charton, P. and Chabriat, J.P. (2013) Clustering Daily Solar Radiation from Reunion Island Using Data Analysis Methods. Renewable Energy and Power Quality, Bilbao, 20-22 March 2013, No. 11.

Submit or recommend next manuscript to SCIRP and we will provide best service for you:

Accepting pre-submission inquiries through Email, Facebook, LinkedIn, Twitter, etc. A wide selection of journals (inclusive of 9 subjects, more than 200 journals)

Providing 24-hour high-quality service

User-friendly online submission system

Fair and swift peer-review system

Efficient typesetting and proofreading procedure

Display of the result of downloads and visits, as well as the number of cited articles Maximum dissemination of your research work

Submit your manuscript at: http://papersubmission.scirp.org/

Or contact sgre@scirp.org 